\title{
Strategi Adaptasi Ojek Konvensional dalam Merespon Adanya Ojek Online di Kota Surakarta
}

\author{
Destiyan Armando Yogi Pratiwi ${ }^{1}$, Nurhadi $^{2}$ dan Abdul Rahman ${ }^{3}$ \\ ${ }^{1}$ Pendidikan Sosiologi Antropologi, Universitas Sebelas Maret \\ Email: destiyanarm@student.uns.ac.id \\ 2 Pendidikan Sosiologi Antropologi, Universitas Sebelas Maret \\ Email: Nurhadi@staff.uns.ac.id \\ ${ }^{3}$ Pendidikan Sosiologi Antropologi, Universitas Sebelas Maret \\ Email: abdulrahman18542@gmail.com
}

\begin{abstract}
Abstrack. The presence of transportation service based applications, including online motorcycle taxis in the city of Surakarta has shifted conventional transportation, especially conventional motorcycle taxis. This makes the conventional motorcycle taxis change their service strategies to maintain their existence. This study aims to (1) explain the conventional motorcycle taxi transportation services and (2) identify the adaptation strategies that have been successfully carried out by conventional motorcycle taxi drivers as work in the city of Surakarta. With a phenomenological / qualitative approach, the researchers involved 9 informants consisting of the coordinator of the Surakarta conventional motorcycle taxi station, the members of the conventional motorcycle taxi, and the Surakarta Community Police Satbinmas. Data about conventional motorcycle taxi services from informants was collected by in-depth interviews. After the transcript the researcher uses the theory of Subsistence Ethics by James C. Scott, which presents 3 choices of strategies: (1) expansion of social networks, (2) alternative entrepreneurship, and (3) savings in household spending. The results showed that conventional motorcycle taxis tried to improve transportation services to their customers and implemented three adaptation strategies: (1) building conventional motorcycle taxi organizations / communities, (2) affirming zoning / service areas and (3) starting other businesses as new sources of income.
\end{abstract}

Keywords : adaptation strategies, conventional motorcycle taxis, and online motorcycle taxis

\begin{abstract}
Abstrak : Kehadiran jasa transportasi berbasis aplikasi, termasuk ojek sepeda motor online di Kota Surakarta telah menggeser transportasi konvensional khususnya ojek sepeda motor konvensional. Hal ini membuat ojek konvensional merubah strategi layanan agar tetap mempertahankan eksistensinya. Penelitian ini bertujuan untuk (1)menjelaskan pelayanan jasa transportasi ojek sepeda motor konvensional dan (2)mengidentifikasi strategi adaptasi yang berhasil dilakukan pengemudi ojek sepeda motor konvensional sebagai pekerjaan di Kota Surakarta. Dengan pendekatan fenomenologis/kualitatif peneliti melibatkan 9 informan terdiri koordinator pangkalan ojek konvensional Surakarta, anggota ojek konvensional, dan Satbinmas Polresta Surakarta. Data tentang pelayanan ojek konvensional dari informan dikumpulkan dengan wawancara mendalam. Setelah transkrip peneliti menggunakan teori Etika Subsistensi karya James C. Scott yang menyajikan 3 pilihan strategi: (1) perluasan jaringan sosial, (2) wirausaha alternatif, dan (3) penghematan pengeluaran belanja rumah tangga. Hasil penelitian menunjukkan bahwa ojek konvensional berusaha memperbaiki pelayanan jasa transportasi kepada pelanggan mereka serta menerapkan tiga strategi adaptasi: (1) membangun organisasi/komunitas ojek konvensional, (2) penegasan zonasi/wilayah layanan dan (3) merintis usaha lain sebagai sumber pendapatan baru.
\end{abstract}

Kata Kunci : strategi adaptasi, ojek konvensional, dan ojek online 


\section{PENDAHULUAN}

Penemuan baru di bidang teknologi menyumbangkan perubahan besar di seluruh Indonesia, termasuk penggunaan transportasi dengan basis aplikasi seperti ojek online di Kota Surakarta. Ojek merupakan salah satu moda transportasi umum sepeda motor untuk mengantar manusia atau barang (Pratiwi \& Haryanto, 2015). Untuk dapat menggunakan jasa ojek (biasa disebut ojek pangkalan/ojek konvensional) pelanggan harus datang ke tempat pangkalan terlebih dahulu. Setelah ojek online hadir, hanya dengan smartphone pelanggan tidak perlu datang ke pangkalan karena pengemudi akan menghampiri ke titik tunggu pelanggan. Menembak harga sebagai ciri khas ojek konvensionalpun tidak digunakan di ojek online. Ojek online memberikan kepastian harga kepada pelanggan yang akan menggunakan jasa ojek online. Hal ini tentu saja menjadikan ojek online lebih unggul dibanding ojek konvensional, akibatnya ojek konvensional semakin ditingalkan.

Berbagai kemudahan yang ditawarkan oleh ojek online mendukung prinsip masyarakat zaman sekarang yang lebih menyukai kemudahan dan kepraktisan. Tidak heran jika ojek online kini menjadi primadona.

Tabel 1.1 Jumlah Pengunduh Transportasi Ojek Online (September 2019)

\begin{tabular}{|l|l|l|}
\hline \multicolumn{1}{|c|}{ No. } & \multicolumn{1}{|c|}{ Nama Aplikasi } & \multicolumn{1}{c|}{ Jumlah Pengunduh } \\
\hline 1. & Gojek & 50 juta download \\
\hline 2. & Grab & 100 juta download \\
\hline 3. & Uber & 500 juta download \\
\hline 4. & My Bluebird & 1 juta download \\
\hline & Total & 651 juta download \\
\hline
\end{tabular}

Dari tabel diatas dapat dilihat bahwa pengguna aplikasi ojek online memasuki angka yang cukup besar. Banyaknya jumlah pengunduh aplikasi ojek online menyumbangkan pertumbuhan industri transportasi online (ride-hailing). Diantara aplikasi ojek online yang tumbuh dan berkembang diatas, hanya dua aplikasi besar yang populer yaitu Gojek dan Grab. Keduanya saling bersaing dan mengembangkan ekspansi ke seluruh kota di Indonesia, termasuk Kota Surakarta. Perkembangan ojek online yang semakin pesat di kota ini pastinya akan berdampak kepada kondisi sosial ekonomi masyarakat Surakarta khususnya pengemudi ojek konvensional sebagai pesaingnya.

Kehadiran ojek online sebagai sesuatu yang baru secara cepat atau lambat pasti dapat menghancurkan ojek konvensional. Dengan demikian diperlukan adanya respon terhadap perubahan kondisi setelah kehadiran transportasi berbasis aplikasi ini. Salah satu bentuk dari respon tersebut ialah dilakukan strategi adaptasi oleh para pengemudi ojek konvensional untuk mempertahankan eksistensinya. Analisis mengenai strategi adaptasi ojek konvensional dalam merespon kehadiran ojek online di Kota Surakarta dirasa dibutuhkan. Untuk itu peneliti mengangkat permasalahan tersebut sebagai fokus penelitian berjudul "Strategi Adaptasi Ojek Konvensional dalam Merespon Adanya Ojek Online di Kota Surakarta."

Kajian mengenai ojek online dan ojek konvensional ini telah banyak dilakukan. Beberapa penelitian terdahulu tersebut antara lain, Konflik Transportasi Ojek Pangkalan dan Ojek Online di Bandung Studi Analisis Tentang Indentitas Budaya Manajemen Konflik dan Teknologi (Diana Anggraeni, 2018) mengkaji mengenai permasalah yang timbul antara ojek online dan ojek pangkalan di Bandung. Kehadiran ojek online yang merubah struktur sosial yang terbangun sebelumnya dan mengambil lahan ojek pangkalan menimbulkan konflik. Peneliti mengkaji bagaimana peran komunikasi dapat menyelesaikan masalah antara keduanya. 
Penelitian lain berjudul Eksistensi Ojek Pangkalan Didalam Perkembangan Transportasi Berbasis Informasi Dan Teknologi (Purwanto, Luthfi, \& Arsal, 2018) mengkaji eksistensi ojek konvensional di Semarang, Jawa Tengah. Dalam penelitian tersebut dijelaskan meskipun untuk saat ini ojek online banyak diminati ek pngkalan tetap dapat menjaga eksistensinya karena ojek pangkalan telah memiliki pelanggan yang loyal yaitu dari kalangan ibu rumah tangga. Selain hal tersebut, solidaritas yang kuat sesama pengemudi ojek pangkalan menjadi kekuatan untuk menjaga eksistensi.

Adapun penelitian berjudul Modal Sosial Ojek Pangkalan Adaptasi Terhadap Aplikasi Online Transportasi Publik (Fathy, 2018) mengkaji kualitas modal sosial yang dimiliki oleh sesama pengemudi ojek pangkalan di Salemba dalam menciptakan ketahanan ekonomi mereka karena persaingan dengan ojek online. Penelitian tersebut membuktikan bahwa semakin baik pengemudi menjaga modal sosial yang dimiliki, semakin tinggi pula ketahanan komunitas tersebut.

Dari penelitian tersebut belum ada yang melihat bagaimana cara adaptasi yang dilakukan pengemudi ojek konvensional secara jelas. Tidak menutup kemungkinan untuk kedepannya transportasi akan terus berkembang dan transportasi konvensional posisinya akan tergeser. Selain itu, mengingat permasalahan yang berkaitan dengan transportasi merupakan permasalahan sosial yang perlu dikaji karena sedikit studi sosiologi yang membahas ini (Usman, Husaini, \& Akbar, 2008).

Adaptasi dalam penelitian ini merupakan proses penyesuaian terhadap lingkungan. Adaptasi dilakukan karena terjadi perubahan dalam lingkungannya. Adapun adaptasi dapat juga dikatakan dengan istilah penyesuaian. Penyesuaian berarti mengubah diri pribadi sesuai dengan keadaan lingkungan atau mengubah lingkungan sesuai keadaan pribadi (Usman, 2005). Begitu pula dengan pengemudi ojek konvensional, mereka juga perlu melakukan penyesuaian dengan lingkungan.

Pendapat lain menurut Soeharto Heerdjan (1987) mengatakan bahwa penyesuaian diri merupakan tindakan yang dilakukan oleh individu ataupun kelompok untuk menghilangkan suatu kesulitan (Sunaryo, 2004). Dengan demikian adaptasi dapat diartikan sebagai sebuah tindakan yang dilakukan oleh individu ataupun kelompok untuk menghilangkan hambatan yang dialami sesuai dengan kondisi yang ada sebagai bentuk penyesuaian diri. Ojek konvensional juga perlu melakukan penyesuaikan diri setelah menghadapi berbagai kesulitan seperti kesulitan untuk mendapatkan pelanggan karena kalah saing dengan ojek online.

Marzali mengatakan bahwa strategi adaptasi merupakan perilaku manusia dalam mengalokasikan sumber daya yang mereka miliki dalam menghadapi masalah-masalah sebagai pilihan dari tindakan yang tepat guna sesuai dengan lingkungan sosial, kultural, ekonomi, dan ekologis dimana mereka hidup (Marzali, 2003). Berdasarkan konsep ini, pengemudi ojek konvensional menghadapi tantangan dan kendala multi dimensional. Tantangan tersebut antara lain ojek konvensional banyak kehilangan pelanggan, sudah tidak menjadi prioritas dan kurang perhatian dari pelanggan, pendapatan semakin turun dan sulit mencari lahan pangkalan.

John Bennet (2005) juga secara tidak langsung mendukung strategi adaptasi dalam mengatasi situasi tertentu. Dia mengatakan bahwa sesorang akan cenderung melakukan siasat apapun untuk menghindari penolakan yang bisa berakibat buruk bagi individu tersebut di masyarakat (Andriani, Susi, \& Jatiningsih, 2015). Jika dikaitkan dengan pengemudi ojek konvensional yang menolak kehadiran ojek online, mereka menolak karena saat ini mereka kehilangan pelanggan yang dapat menurunkan pendapatan dan tidak mampu menghidupi keluarga.

Dari beberapa penjelasan diatas, secara umum strategi adaptasi dapat diartikan sebagai sebuah rencana tindakan yang dilakukan manusia secara sadar ataupun tidak untuk menghadapi masalahnya. Dalam penelitian ini, peneliti menjabarkan upaya yang dilakukan ojek konvensional sebagai strategi adaptasi dalam merespon kehadiran ojek online di Kota Surakarta.

Strategi Adaptasi dalam Etika Subsistensi karya James C. Scott. Dalam buku Moral Ekonomi Petani, James C Scott menjelaskan pertahanan kaum petani di Asia Tenggara yang mengalami krisis seperti gagal panen sehingga para petani kesulitan dalam menjalankan hidup (akibat wabah kelaparan). Agar tetap bertahan, para petani harus melakukan siasat agar mereka mampu memenuhi kebutuhan pangan mereka. Para petani ini memegang prinsip yang dinamakan prinsip 
utamakan selamat atau "safety first" yaitu prinsip petani untuk berjaga - jaga mempersiapkan gagal panen dengan menanam tumbuhan bahan pokok ketimbang menanam tanaman komersial yang memiliki peluang keuntungan besar (C.Scott, 1981). Adapun tiga strategi yang dilakukan oleh kaum petani yaitu :

1) Membangun relasi atau jaringan sosial

Meminta bantuan dari relasi atau jaringan sosial seperti sanak saudara, kawan-kawan sedesa, atau memanfaatkan hubungan dengan pelindungnya (patron) / memanfaatkan hubungan patronase, dinamakan ikatan patron dan klien merupakan salah satu bentuk asuransi dikalangan petani.

2) Alternatif subsistensi/ swadaya

Menggunkan alternatif subsisten yaitu swadaya yang mencakup kegiatan seperti berjualan kecil-kecilan, bekerja sebagai tukang, sebagai buruh lepas atau melakukan migrasi untuk mencari pekerjaan. Cara ini dapat melibatkan seluruh sumber daya yang ada di dalam rumah tangga miskin, terutama istri sebagai pencari nafkah tambahan bagi suami.

3) Mengikat sabuk lebih kencang/Membatasi Diri

Mengurangi pengeluaran untuk pangan dengan jalan makan hanya sekali sehari dan beralih kemakanan yang mutunya lebih rendah, seperti beralih makan jewawut atau umbi-umbian (Nugraha, 2017).

Dalam konteks pengemudi ojek konvensional yang mengalami kondisi krisis akibat tergeser oleh adanya transportasi berbasis aplikasi seperti ojek online, pengemudi ojek konvensional perlu melakukan berbagai adaptasi untuk mengatasi hambatan seperti berkurangnya pendapatan akibat pelanggan yang semakin sedikit, lahan pangkalan yang semakin sempit, serta keterbatasan dalam menggunakan teknologi. Para ojek konvensional harus mampu memperbaiki pelayananan untuk mengembalikan kepercayaan pelanggan dan demi keberlangsungan eksistensi ojek konvensional.

\section{METODE PENELITIAN}

Peneliti menggunakan metode penelitian kualitatif. Data penelitian diperoleh melalui wawancara mendalam ke sembilan informan yang tersebar di tiga lokasi pangkalan konvensional, yaitu : Terminal Tirtonadi, Stasiun Balapan, dan Stasiun Purwosari. Lokasi tersebut dipilih karena rentan terjadi konflik sosial antara pengemudi ojek konvensional dan ojek online dalam meperebutkan penumpang. Dalam penelitian ini, informan (sumber data) dipilih secara purposive dan bersifat snowball sampling. Data yang diperoleh dianalisis melalui tahap pengumpulan data, reduksi data, penyajian data, penarikan kesimpulan dan menggunakan teknik keabsahan data triangulasi sumber.

\section{HASIL DAN PEMBAHASAN}

\section{Pelayanan Jasa Transportasi Ojek Konvensional di Kota Surakarta}

Kehadiran ojek online mengakibatkan ojek konvensional berada dalam posisi termarginalisasi oleh ojek online, jumlah pengojek semakin sedikit dan pelanggan semakin terbatas. Pendapatan yang semakin kecil membawa pengemudi ojek konvensisonal berada dalam kondisi krisis. Untuk itu pengemudi ojek konvensional harus menghadapi tantangan dan adaptasi lingkungan dengan cara melakukan perbaikan pelayanan jasa transportasi supaya digemari masyarakat pelanggan. Mengikuti pemikiran Gerungan dalam karya Usman pengojek konvensional perlu mengubah diri pribadi sesuai dengan keadaan lingkungan atau menciptakan lingkungan baru yang menguntungkan kebutuhan hidupnya sebagai pengojek konvensional (Usman, 2005). Dengan adaptasi lingkungan, pribadi maupun kolektif, pengojek konvensional beruasaha memberikan pelayanan cepat, murah dan sikap sopan.

Berdasarkan hasil temuan di tiga lokasi pangkalan ojek, peneliti mengelompokkan empat aspek pelayanan yang dilakukan oleh pengemudi ojek konvensional. Pelayanan tersebut antara lain: 
1. Jaringan Sosial Ojek Konvensional.

Semenjak kehadiran ojek online di Kota Surakarta, pangkalan ojek konvensional menjadi sepi pelanggan. Beberapa penumpang yang biasanya berlangganan telah berpindah ke layanan ojek online. Dalam dunia bisnis, membangun relasi dengan pihak lain bermanfaat untuk mengembangkan usaha. Hal ini juga berlaku pada ojek konvensional. Pengemudi ojek konvensional membagi nomer telepon mereka ke pelanggan. Dengan tersebar luasnya nomer teleponnya ojek, jaringan pelanggan ojek konvensional akan semakin luas sehingga pendapatan mereka melimpah.

2. Pengetahuan Ojek Online Oleh Ojek Konvensional.

Para pengemudi ojek konvensional berusaha melakukan hal yang berbeda dari ojek online.

\section{Para ojek konvensional menyediakan beberapa pelayanan yang dijadikan unggulan. Beberapa pelayanan tersebut antara lain :}

1) Ojek konvensional dapat melayani jasa antar ke luar Kota Surakarta tanpa batasan waktu. Hal ini sering terjadi di pangkalan ojek Terminal Tirtonadi, Stasiun Balapan dan Stasiun Purwosari. Pelanggan biasa menggunakan pelayanan ini karena mereka sudah tertinggal bus tau kereta yang akan mereka tumpangi.

2) Ojek online tidak menggunakan aplikasi merupakan kelebihan. Hal ini membuat ojek konvensional bersahabat dengan pelanggan dari kalangan orang tua yang kesulitan dalam menggunakan smarthphone.

3) Dalam menentukan harga jasa, ojek konvensional menggunakan sistem tawar menawar. Pelanggan dapat menyesuaikan jarak tempuh yang akan dilalui dengan budget yang dimiliki. Bahkan para pengemudi ojek konvensional memasang tarif yang berbeda antara pelanggan yang masih bersekolah dengan pelanggan umum. Alasan mereka melakukan ini adalah untuk menarik semua kalangan agar tetap menggunakan jasa ojek konvensional. Menurut para pengemudi ojek konvensional, hal tersebut merupakan keistimewaan yang tidak ada pada ojek online.

c. Etos Kerja. Etos kerja merupakan sikap yang muncul atas kehendak dan kesadaran diri yang didasari oleh sistem orientasi nilai terhadap kerja (Sukardewi, Nyoman, \& et all, 2013). Dalam keseharian etos kerja sesorang akan menunjukkan kualitas dalam melakukan pekerjaan. Berdasarkan data yang dikumpulkan, para pengemudi ojek konvensional ingin bekerja secara fleksibel dan santai. Mereka tidak ingin terikat dengan siapapun. Menurut para pengemudi ojek konvensional, ketika mereka menjadi pengemudi ojek online mereka justru merasa harus bekerja lebih keras karena mereka harus kejar poin. Hal ini pula yang mendasari pengemudi ojek konvensional di Surakarta yang masih bertahan untuk tidak pindah ke ojek online. Bahkan mayoritas pengemudi ojek online Solo Raya sepakat untuk tetap bertahan sebagai pengemudi ojek konvensional. Dengan adanya dukungan sesama pengemudi ojek pangkalan, hal ini menambah semangat pengemudi untuk terus eksis.

d. Kelayakan (standar mutu) sepeda motor

Sepeda motor merupakan barang yang sangat berharga bagi para pengemudi ojek konvensional. Mereka peduli dengan kondisi sepeda motor yang dipakai. Jika motor mereka rusak atau bermasalah maka para pengemudi ojek konvensional tidak dapat bekerja. Bahkan kondisi sepeda motor dijadikan pertimbangan oleh para pengemudi ojek konvensional untuk tetap bekerja sebagai ojek konvensional dan enggan beralih sebagai pengemudi ojek online. Para pengemudi ojek konvensional yang peneliti temui beranggapan bahwa ketika mereka pindah menjadi pengemudi ojek online, hal itu justru akan membuat motor yang digunakan akan terus terforsir sehingga mudah rusak. Mengingat tingginya jam kerja pengemudi ojek online. Untuk itu demi meningkatkan mutu pelayanan para pengemudi ojek konvensional memperhatikan kenyamanan penumpang saat berkendara, meskipun motor yang mereka gunakan bukan motor keluaran baru. 
Sejalan dengan teori yang disampaikan Scott mengenai kaum petani yang menggunakan prinsip mengutamakan selamat, para pengemudi ojek konvensional di Kota Surakarta secara mayoritas sepakat memilih untuk bertahan sebagai pengemudi ojek konvensional. Para pengemudi ojek konvensional sadar betul akan konsekuensi jika mereka tetap bertahan. Konsekuensi tersebut antara lain berkurangnya pelanggan, pendapatan semakin menurun dan berujung pada pemenuhan kebutuhan keluarga yang terganggu. Hal ini telah mereka pertimbangkan. Tak sedikit dari pengemudi konvensional yang ada, menjadikan pekerjaan sebagai pengemudi ojek konvensional sebagai pekerjaan sampingan yang sifatnya fleksibel. Adapun yang tidak menjadikan pekerjaan pengemudi ojek konvensional sebagai sampingan, mereka memiliki tambahan penghasilan lain. Dari ini didapat pola bahwa para pengemudi ojek konvensional yang memilih untuk bertahan tidak mengejar pendapatan yang besar yang hanya dapat dinikmati untuk saat ini saja, namun mereka berjaga - jaga apabila mereka bergabung menjadi ojek online justru persaingan lebih sulit mengingat pengemudi ojek online juga mengalami peningatan.

\section{Strategi Adaptasi Ojek Konvensional melalui Etika Subsistensi}

a. Pembatasan Wilayah

Para pengemudi ojek konvensional di Kota Surakarta adalah korban beroperasinya ojek online. Mereka semakin sulit memenuhi kebutuhan layak hidup. Mayoritas pengemudi ojek konvensional dalam menghadapi situasi ini telah mencoba mengurangi resiko negatif seperti krisis pemenuhan makan, pakaian, dan tempat tinggal bagi keluarga mereka. Layaknya masyarakat petani, komunitas pengemudi ojek konvensional, menyelamatkan hidup para pengemudi ojek konvensional, di tengah maraknya ojek online. Mereka berdiskusi dan berinisiasi bersama, membangun kepercayaan kolektif, menemui kantor perwakilan ojek online, menawarkan zonasi pelayanan ojek, membuat kesepakatan, yang dinamakan zona merah, di area pangkalan ojek konvensional. Sesuai dengan konsep etika subsistensi, pengemudi oline dengan ikhlas memahami tanggungjawab kehidupan nasib pengemudi terhadap kondisi keluarga ojek konvensional. Kedua pihak, sepakat ada Zona Merah. Zona merah merupakan batasan kawasan ojek online untuk mengambil penumpang di kawasan kekuasaan ojek konvensional. Para pengemudi ojek konvensional menghindari resiko adanya perebutan penumpang di kawasan pangkalan mereka dan upaya menyelamatkan pendapatan mereka agar penumpang yang berasal dari wilayah pangkalannya tidak beralih ke ojek online.

\section{b. Penghasilan tambahan}

Upaya lain selain mengutamakan selamat dalam menghindari krisis pangan, sandang, dan papan yang sedang menimpa mereka, pengemudi ojek konvensional meniru masyarakat petani. Mereka menggunakan siasat berupa alternatif subsisten atau "swadaya" dimana masyarakat pengemudi dan keluarga mereka berusaha menambah penghasilan dengan kegiatan diluar layanan ojek. Mereka merintis berjualan kecil-kecilan, menjadi pengemudi mobil pribadi, buruh lepas di proyek bangunan, bahkan sampai berpindah tempat tinggal di kota lain. Cara ini dapat melibatkan seluruh sumber daya yang ada di dalam rumah tangga miskin. Saat ini istri juga berperan sebagai pencari nafkah tambahan bagi suami, pengemudi ojek. Hal ini dilakukan agar kebutuhan pangan mereka tercukupi dengan tambahan penghasilan.

Apabila kita bandingkan dengan konteks pengemudi ojek konvensional merespon kehadiran ojek online di Kota Surakarta, para pengemudi ojek konvensional ini juga melakukan apa yang dinamakan dengan alternatif subtensi. Para pengemudi ojek konvensional mencari tambahan pekerjaan lain untuk pemasukan, bahkan sebagian besar dari pengemudi ojek yang peneliti temui kini telah menjadikan pekerjaan ojek sebagai pekerjaan sampingan. Meskipun sampingan, mereka mengaku tetap bertanggung jawab penuh seperti melakukan pekerjaan tetap. Hal ini mereka lakukan istilahnya "agar dapur tetap ngebul" atau dapat diartikan agar kebutuhan sehari hari tetap terpenuhi meskipun pendapatan dari ngojek minim. Mereka percaya bahwa rejeki telah diatur oleh Tuhan dan tugas mereka hanyalah berusaha untuk mencarinya. 
Komunitas pengemudi ojek konvensional senasib dengan masyarakat petani, di Indonesia maupun di Asia Tenggara. Mereka memiliki latar belakang kondisi sosial budaya masyarakat desa, rendah pendidikan, sulit akses modal keuangan di lembaga jasa keuangan, dan lainnya. Pengemudi dari desa menyamakan hadirnya ojek online seperti bencana alam - mereka dipaksa menghadapinya. Dalam mengatasi hal-hal tersebut, mereka muncul ide dan perilaku subsistensi. Mereka membentuk hubungan resiprokal berupa hubungan "patron-klien" yang selalu mereka jaga. Kebersamaan nasib sesama pengemudi melembaga, dilakukan oleh orang banyak dan berulang-ulang - ini proses sosial masyarakat perdesaan, tapi berjalan dalam kehidupan masyakat kota sebagai pengemudi ojek demi pemenuhan kebutuhan ekonomi mereka.

\section{c. Paguyuban Pengemudi Ojek Konvensional}

Konsep patron-clien dari Scott menjelaskan hubungan resiprokal antara kedua belah pihak antara lain patron yang berperan sebagai sumber penghidupan subsistensi dasar, menjamin krisis subsistensi, perlindungan, makelar, serta jasa kolektif bagi klien, sedangkan klien berperan sebagai penyedia tenaga dan keahlianya untuk kepentingan patron. Ikatan patron - klien masyarakat pengemudi (meniru petani desa) ini dapat menjadi salah satu bentuk asuransi di kalangan pengemudi.

Dalam menjalankan strategi adaptasi para pengemudi ojek konvensional juga terjalin hubungan resiprokal dengan sesama pengemudi ojek konvensional se-Kota Surakarta dalam bentuk Paguyuban Ojek Solo Raya dan pihak pihak lain yang terkait seperti pihak Satbinmas (Satuan Pembinaan Masyarakat) Polres Surakarta sebagai pembina paguyuban. Tiap individu dari pengemudi ojek konvensional ini awalnya terbentuk dari paguyuban tiap pangkalan kemudian dibentuklah sebuah paguyuban besar bernama Paguyuban Ojek Solo Raya (POSR) yang dapat merangkul seluruh pengemudi ojek konvensional dari pangkalan manapun asalkan masih dalam Kota Surakarta. Dari sini kemudian timbullah hubungan yang memperkuat relasi sesama ojek konvensional di Kota Surakarta.

Terbentuknya paguyuban ojek konvensional baik dalam tiap pangkalan maupun paguyuban besar Solo Raya hubungan resiprokal dapat dilihat melalui contoh dimana setiap ada anggota paguyuban yang tertimpa musibah akan mendapat santunan dari hasil iuran bersama per harinya. Diakui oleh beberapa informan peneliti hal ini sedikit meringankan beban si penerima santunan, meskipun mereka tidak berharap mendapat santunan karena mereka tidak ingin ada musibah yang menimpa mereka. Uang iuran yang mereka bayarkan pada paguyuban seakan menjadi asuransi mereka. Uang iuran yang rutin mereka bayarkan tersebut dapat mereka pinjam ketika mereka membutuhkan mereka membutuhkan.

Tergabungnya pengemudi ojek konvensional di Kota Surakarta dalam satu paguyuban dibawah bimbingan Satbinmas Polres Kota Surakarta menjadikan posisi pengemudi ojek konvensional dalam perlindungan resmi Satbinmas Polres Kota Surakarta apabila terjadi sesuatu diantara mereka. Hal ini dibuktikan dengan kartu keanggotaan (KTA) yang mereka miliki merupakan pemberian dari pihak Satbinmas Polres Kota Surakarta dan pihak Satbinmas Polres Kota Surakarta memiliki tanggung jawab terhadap anggota yang tergabung dalam paguyuban. Dalam upaya menjaga relasi, Satbinmas Polres Kota Surakarta dan anggota mengadakan acara pertemuan yang tidak melulu membahas mengenai masalah serius sesekali terdapat pertemuan yang sifatnya santai seperti acara buka bersama. Hal ini sangat bermaanfaat bagi keberlangsungan karir mereka dalam bekerja sebagai pengemudi ojek konvensional. Dengan adanya paguyuban dibawah bimbingan langsung Satbinmas Polres Kota Surakarta, para pengemudi ojek konvensional merasa terlindungi terutama ketika nantinya berkonflik dengan oknum ojek online yang melanggar kesepakatan. Selain itu, pengemudi ojek konvensional merasa mendapat dukungan dari pihak pemerintah untuk mempertahankan pekerjaan ojek konvensional. 


\section{KESIMPULAN}

Dalam melakukan pelayanan jasa transportasi, ojek konvensional di Kota Surakarta berusaha untuk memperbanyak relasi dengan membagi nomer ke pelanggannya. Kedua berbekal pengetahuan pelayanan di ojek online para pengemudi ojek konvensional melakukan beberapa hal yang berbeda yang tidak dapat dilakukan oleh ojek online, Kemudian dalam melakukan pelayanan jasa transportasi para pengemudi ojek konvensional berupaya memperhatikan standar mutu sepeda motor mereka. Sedangkan dalam upaya melakukan strategi adaptasi ojek konvensional di Kota Surakarta memiliki beberapa siasat seperti melakukan optimalisai komunitas dengan membentuk satu wadah paguyuban ojek konvensional Solo Raya, melakukan pembatasan wilayah dengan adanya zona merah dan menciptakan sumber pendaptan baru selain mengojek seperti membuka kos-kosan, petani, kerja buruh pabrik atau buka toko.

\section{DAFTAR PUSTAKA}

Andriani, Susi, \& Jatiningsih. (2015). Strategi Adaptasi Sosial Siswa Papua di Kota Lamongan. Jurnal Kajian Moral Dan Kewarganegaraan, 2(3), 530-544.

C.Scott, J. (1981). Moral Ekonomi Petani. Jakarta: PT Intermasa.

Diana Anggraeni. (2018). Konflik Transportasi Ojek Pangkalan dan Ojk Online di Bandung (Studi Analisis Tentang Identitas Budaya, Manajemen Konflik, dan Teknologi. Comunicare, 4, 4156.

Fathy, R. (2018). Modal Sosial Ojek Pangkalan : Adaptasi Terhadap Aplikasi Online Transportasi Publik. Masyarakat Dan Budaya, 20(2), 191-210.

Marzali, A. (2003). Strategi Peisan Cikalong dalam Menghadapi Kemiskinan. Jakarta: Yayasan Obor. Nugraha, H. S. (2017). Strategi Bertahan Hidup Petani di Kelurahan Made, Surabaya. E-Jurnal.

Pratiwi, R., \& Haryanto, R. (2015). Kajian Keberadaan Ojek Sebagai Angkutan Umum Paratransit Di Kota Semarang ( Studi Kasus: Koridor Jalan Kesatrian, Jalan Ngatrep Timur V Dan Jalan Karangrejo Raya). Jurnal Pembangunan Wilayah Dan Kota, 11(3), 351-364.

Purwanto, A. C., Luthfi, A., \& Arsal, T. (2018). Eksistensi Ojek Pangkalan Didalam Perkembangan Transportasi Berbasis. SOLIDARITY, 7(1), 243-255.

Sukardewi, Nyoman, \& et all. (2013). Kontribusi Adversity Quotient (AQ) Etos Kerja dan Budaya Prganisasi terhadap Kinerja Guru SMA Negeri di Kota Amlapura. Akuntansi Pascasarjana Universitas Syiah Kuala, 4.

Sunaryo. (2004). Psikologi Untuk Keoerawatan. Jakarta: EGC.

Usman, S. (2005). Esai-Esai Sosiologi Perubahan Sosial. Jogjakarta: Pustaka Pelajar.

Usman, Husaini, \& Akbar, P. S. (2008). Metode Penelitian Sosial. Jakarta: Bumi Aksara. 